\title{
Root canal therapy, fixed partial dentures and implant- supported crowns, have similar short term survival rates
}

\author{
What is the most effective way of restoring an abscessed tooth, nonsurgical \\ endodontic treatment, extraction and implant placement, extraction and fixed \\ partial denture, extraction without tooth replacement?
}

\begin{abstract}
Torabinejad M, Anderson P, Bader J, et al.
Outcomes of root canal treatment and restoration,

implant-supported single crowns, fixed partial dentures, and extraction without replacement: a systematic review. J Prosthet Dent 2007; 98:285-283
\end{abstract}

Data sources Searches using the Medline, Cochrane and Embase
databases and 'citation mining' ( identifying references from included
studies ) were carried out. In addition, experts' recommendations for
data sources were followed, and the table of contents of every issue of
the most recent 2 years of a given list of dental journals were reviewed,
the latter representing half of the total number of original research arti-
cles in English from the past 5 years on implant-supported crown (ISC),
fixed partial dentures (FPD) and root canal (RC) therapy. Publication lan-
guage was limited to English and grey literature was excluded, namely
proceedings of conferences not listed in Medline, Cochrane or Embase
databases, meetings and lectures. Study selection Comparative or noncomparative, prospective or retrospective longitudinal data were selected that related to clinical, biological, psychological and economic outcomes, as well as beneficial or harmful effects, of saving teeth by root canal treatment and/ or alternative treatments, including: extracting the tooth and leaving an edentulous space or replacing the missing tooth with a fixed-partial-denture or implant-supported tooth.

Data extraction and synthesis Three pairs of investigators (each team dealing with one of the three main treatment options) independently searched, selected and extracted data for analysis. Tables of evidence were created from articles that met the validity criteria. Each selected paper was given a quality score, where the maximum possible was 17. Discussion and consensus were used to resolve disagreement. Interpretation of the outcome data and classification of data according to success or survival and the type of study were verified by two statisticians. Qualitative and quantitative methods were used to integrate the evidence. The data were analysed by deciding whether and what data to combine, and measuring the statistical heterogeneity of the data using Cochrane $\mathrm{Q}$ and $\mathrm{I}^{2}$ statistics. For the purpose of comparison, clinical outcomes were grouped into three time-intervals (2-4 years, 4-6 years and $>6$ years). Each discipline and followup interval from individual studies were displayed in a Forest plot with Wilson Score $95 \%$ confidence intervals. Meta-analysis produced pooled points and weighted averages. Psychosocial and economic outcome data was subjected to narrative review only.

Results The 143 selected studies varied considerably in design, definition of success, assessment methods, operator type and sample size. Direct comparison of treatment types was extremely rare. Limited

Address for correspondence: Dr Shane N White, University of California-Los Angeles School of Dentistry, 10833 Le Conte Avenue, Room CHS 23-010, Los Angeles CA 90095-1668, USA. E-mail: snwhite@dentistry.ucla.edu psychosocial data revealed the traumatic effect of loss of visible teeth. Economic data were largely absent. Success rates for ISC were higher than for RC treatment with direct or indirect restoration and FPD, respectively. Success criteria, however, differed greatly between treatment types, rendering direct comparison of success rates futile. Longterm survival rates for ISC and RC therapy were similar and superior to those for FPD.

Conclusions The lack of studies with similar outcome criteria and comparable time intervals limited the ability to make valid comparisons between these treatments. It was possible to conclude that ISC and RC treatments have superior long-term survival compared with FPD. Limited data suggested that extraction without replacement resulted in inferior psychosocial outcomes compared with alternatives. Long-term prospective clinical trials with large sample sizes and clearly defined outcome criteria are needed.

\section{Commentary}

Dentists are often requested to assist in recommending optimal treatment plans for their patients. The objective of this review was to help the dentist through this process by evaluating and summarising the current literature on the prognosis, preferences and economics of managing an abscessed tooth. The authors systematically review the following four treatment options:

1. save the tooth via $\mathrm{RC}$ therapy and then restore it with either a direct or indirect restoration;

2. extract the tooth and leave an edentulous space;

3. extract the tooth and replace it with a FPD; or

4. extract the tooth and replace it with an ISC.

This is the third systematic review published in 2007 that tried to compare the prognosis between these options (Tables 1-3) 1,2 and all of them arrived at similar 5-year prognostic estimates (Table 3 ). This does demonstrate the soundness of the systematic review methodology in evaluating scientific literature in this discipline.

Although this review presents a generally high survival rate, of 6 years or longer, for RC treatment and ISC (in well over $90 \%$ of cases), it estimated significantly lower rates for FPD. This led the authors to conclude that ISC and RC treatments resulted in superior longer-term survival than FPD. I suggest caution, however, when interpreting their estimates of longer than 6 years. These "long term survival [rates]" are of limited value since followup time included treatments completed between 7 and 20 years. Ideally, a meta-analysis using the actuarial analysis method described by Lindh et al. (1998), ${ }^{3}$ would have offered yearly survival estimates carrying greater weight. Such an analysis requires good quality Kaplan-Meyer survival data, though, which may not have been available in many of the studies reviewed.

In addition, the PICO (problem, intervention, comparison outcome) question specified the replacement of a single tooth area, 
Table 1. PICO (problem, intervention, comparison outcome) questions.

\begin{tabular}{|c|c|}
\hline Article & PICO question \\
\hline \multirow[t]{4}{*}{ Torabinejad et al., 2007} & In patients with periodontal sound teeth that have pulpal and/ or periradicular pathosis does ... \\
\hline & $\begin{array}{l}\text {... nonsurgical RC therapy, compared to extraction without replacement of the missing tooth, result in better (more } \\
\text { beneficial) or worse (more harmful) clinical and/ or biological outcomes, psychosocial outcomes, and economic } \\
\text { outcomes? }\end{array}$ \\
\hline & $\begin{array}{l}\ldots \mathrm{RC} \text { therapy, compared to extraction and replacement of the missing tooth, with a FPD result in better or worse } \\
\text { outcomes? }\end{array}$ \\
\hline & $\begin{array}{l}\text {...RC therapy, compared to extraction or replacement of the missing tooth, with an ISC, result in better or worst } \\
\text { outcomes? }\end{array}$ \\
\hline Salinas and Eckert, 2007 & How does the success and /or survival of ISC compare to FPD? \\
\hline Iqbal and Syngcuk, 2007 & How does the success and or survival of ISC compare to restored endodontic tooth (RC treatment)? \\
\hline
\end{tabular}

Table 2. Methods

\begin{tabular}{|c|c|c|c|c|c|c|}
\hline Article & Inclusion vs exclusion & $\begin{array}{l}\text { Search strategy } \\
\text { given }\end{array}$ & $\begin{array}{l}\text { Data extraction } \\
\text { and analysis }\end{array}$ & $\begin{array}{l}\text { Date of } \\
\text { search }\end{array}$ & Initial hits & $\begin{array}{l}\text { Final } \\
\text { inclusion }\end{array}$ \\
\hline $\begin{array}{l}\text { Torabinejad et al., } \\
2007\end{array}$ & $\begin{array}{l}\text { Comparative and non } \\
\text { comparative, prospective or } \\
\text { retrospective, longitudinal data. } \\
\text { Clinical, biological, psychosocial } \\
\text { and economic outcomes. } \\
\text { Limited to English language }\end{array}$ & $\begin{array}{l}\text { Medline, Cochrane, } \\
\text { Embase databases; } \\
\text { hand search, (authors } \\
\text { list } 17 \text { journals); } \\
\text { citation mining; } \\
\text { expert suggestions }\end{array}$ & $\begin{array}{l}\text { Success and survival } \\
\text { (grouped into 2- } \\
4 \text { years, 4-6 years, } \\
6+\text { years); Forest } \\
\text { plots and Wilson's } \\
95 \% \mathrm{Cl}\end{array}$ & $\begin{array}{l}\text { Sept } \\
2006\end{array}$ & $\begin{array}{l}\text { ISC, } 4361 ; \\
\text { FPD, } \\
3340 ; \text { RC } \\
\text { treatment, } \\
5346\end{array}$ & $\begin{array}{l}\text { ISC } 46 ; \\
\text { FPD, } 31 ; \text { RC } \\
\text { treatment, } \\
24\end{array}$ \\
\hline $\begin{array}{l}\text { Salinas and } \\
\text { Eckert, } 2007\end{array}$ & $\begin{array}{l}\geq 2 \text { years of clinical survival with } \\
\geq 12 \text { restorations. Limited to } \\
\text { English language }\end{array}$ & $\begin{array}{l}\text { Medline, Cochrane, } \\
\text { Embase databases; } \\
\text { hand search; citation } \\
\text { mining }\end{array}$ & $\begin{array}{l}\text { Survival Forest plots } \\
\text { and Wilson's } 95 \% \mathrm{Cl}\end{array}$ & $\begin{array}{l}\text { May } \\
2005\end{array}$ & 1766 (total) & $\begin{array}{l}\text { ISC, 54; FPD, } \\
41\end{array}$ \\
\hline $\begin{array}{l}\text { lqbal and } \\
\text { Syngcuk, } 2007\end{array}$ & $\begin{array}{l}\mathrm{RCT} \text {, prospective and } \\
\text { retrospective cohorts, } \\
\text { prospective and retrospective } \\
\text { case series } \\
\text { Follow-up } \geq 1 \text { year } \\
\text { Sample size } \geq 10 \\
\text { Language limitations not clear }\end{array}$ & $\begin{array}{l}\text { Medline, PubMed, } \\
\text { Embase databases; } \\
\text { hand search; citation } \\
\text { mining }\end{array}$ & $\begin{array}{l}\text { Survival Forest plots } \\
\text { and Wilson's } 95 \% \mathrm{Cl}\end{array}$ & $\begin{array}{l}\text { May } \\
2005\end{array}$ & $\begin{array}{l}\text { ISC, } \\
1797 ; \text { RC } \\
\text { treatment, } \\
430\end{array}$ & $\begin{array}{l}\text { ISC 55; RC } \\
\text { treatment, } \\
35\end{array}$ \\
\hline
\end{tabular}

CI, Confidence interval; RC, root canal; FPD, fixed partial denture; ISC, implant-supported restoration

yet the review limited the design and size of the fixed appliance to three- and four-unit bridges, including cantilever bridges. The pooled analysis also included conventional FPD with resin-bonded dentures ('Maryland bridges'). Such heterogeneity in the treatment design of FPD may explain the wider confidence interval of the estimates compared with the success rate of RC treatment and ISC. (Note that I am referring here to the $>6$ year success rate estimate and not the survival rate estimate because the latter was taken from a single study of resin-bonded FPD.) Also, the inclusion of resinbonded dentures probably had a downward effect on the estimated success or survival, as shown by Salinas and Eckert (2007). In that review, excluding resin-bonded FPD from the meta-analysis calculation meant the pooled 5-year survival rate estimated of a conventional FPD was comparable to that of the already high survival estimates for the RC treatment and ISC.

Another limitation of this systematic review is the relatively short time frame of about 6 years, especially when you consider that dental caries is the most common cause of prosthetic failure in the long term. ${ }^{4,5}$ Long-term followup studies of 10-20 years may show ISC outperforming the alternatives.

Even though the authors assessed the quality of the studies to be poor to fair, the generally high survival rates (with associated narrow confidence intervals and consistent with the other reviews) for RC treatment, ISC and conventional FPD indicate that the decision on how to manage an abscessed tooth (at least in the 5-6 year timeframe) should be based on factors other than prognosis, namely: prognostic risk factors (smoking, caries activity), patient preferences and economics.

Torabinejad and colleagues tried to determine the specifics of these factors by including psychosocial and economic aspects of each treatment option in their PICO questions. Unfortunately, a limited number of economic studies were found. Furthermore, the various ways psychosocial factors were reported made it impossible to calculate any summary statistic. This indicates that, currently, a void exists in the literature in this area. I am aware of only one study that quantitatively assesses the utility and eco- 


\begin{tabular}{|c|c|c|c|c|}
\hline Article & Treatment & $\begin{array}{l}\text { Duration } \\
\text { (years) }\end{array}$ & $\begin{array}{l}\text { Success } \\
{[\%(95 \% \mathrm{CI})]}\end{array}$ & $\begin{array}{l}\text { Survival } \\
{[\%(95 \% \mathrm{CI})]}\end{array}$ \\
\hline \multirow[t]{6}{*}{ Torabinejad et al., 2007} & ISC & $2-4$ & $99(96-100)$ & $96(94-97)$ \\
\hline & & $4-6$ & $98(97-99)$ & $97(95-98)$ \\
\hline & & $4-6$ & $82(71-91)$ & $93(87-96)^{*}$ \\
\hline & & $6+$ & $81(74-86)$ & $82(80-84)^{*}$ \\
\hline & $\mathrm{RC}$ treatment & $2-4$ & $90(88-92)$ & \\
\hline & & $4-6$ & $93(87-97)$ & $94(92-96)$ \\
\hline Salinas and Eckert, 2007 & FPD (conventional) & 5 & $94(91-97)$ & \\
\hline \multirow[t]{2}{*}{ Iqbal and Syngcuk, 2007} & ISC & 5 & $96(94-97)$ & \\
\hline & $\mathrm{RC}$ treatment & 5 & $94(91-96)$ & \\
\hline
\end{tabular}

nomics of managing an abscessed tooth through a decision-tree analysis. It concluded that the, "position of the abscessed tooth and the amount of insurance coverage influences the utility and [preference] rank assigned by patients to the different treatment options". ${ }^{6}$ Considering the importance of these factors in evidence-based decision-making by the stakeholders in oral healthcare, I suggest that future research resources be directed towards quantitative analysis of the utility and economics of various dental treatment options.

\section{Practice points}

In the short term, RC treatment, FPD and ISC have equally high success and survival rates.

The decision on how to manage an abscessed tooth (in the 5-6 year timeframe) should be based on factors other than prognosis, namely prognostic risk factors (medical history, smoking, caries), patient preferences and economics.

\section{Ben Balevi}

Dental Practitioner, Vancouver, British Columbia, Canada

1. Salinas TJ, Eckert SE. In patients requiring single-tooth replacement, what are the outcomes of implant- as compared to tooth-supported restorations? Int J Oral Maxillofac Implant 2007; 22(suppl.):S71-S95.

2. Iqbal MK. For teeth requiring endodontic treatment, what are the differences in outcomes of restored endontically treated teeth compared to implant-supported restorations? Int J Oral Maxillofac Implant 2007; 22(suppl.):S96-S116.

3. Lindh T, Gunne J, Tillberg A, Molin M. A meta-analysis of implants in partial edentulism. Clin Oral Implant Res 1998; 9:80-90.

4. Aquilino SA, Shugars DA, Bader JD, White BA. Ten-year survival rates of teeth adjacent to treated and untreated posterior bounded edentulous spaces. J Prosthet Dent 2001; 85:455-460.

5. Walton TR. An up to 15 -year longitudinal study of 515 metal-ceramic FPDs. Part 2. Modes of failure and influence of various clinical characteristics. Int J Prosthodont 2003; 16:177-182.

6. Balevi B, Shepperd S. The management of an endodontically abscessed tooth: patient health state utility, decision-tree and economic analysis. BMC Oral Health 2007; 7:17.

Evidence-Based Dentistry (2008) 9, 15-17. doi:10.1038/sj.ebd.6400565 